\title{
ROLE OF HIGH FREQUENCY ULTRASOUND AND COLOUR DOPPLER IN EVALUATION OF SCROTAL PATHOLOGIES
}

\author{
Dheeraj Raj S. M11, Ramakrishna Y2, Karthik Aithal ${ }^{3}$
}

${ }^{1}$ Assistant Professor, Department of Radiology, Srinivas Institute of Medical Sciences and Research Centre, Mukka, Mangalore. ${ }^{2}$ Associate Professor, Department of General Surgery, Srinivas Institute of Medical Sciences and Research Centre, Mukka, Mangalore. ${ }^{3}$ Assistant Professor, Department of General Surgery, Srinivas Institute of Medical Sciences and Research Centre, Mukka, Mangalore.

\begin{tabular}{l}
\hline ABSTRACT \\
\hline BACKGROUND \\
High frequency ultrasonography with colour Doppler is highly accurate and sensitive modality for investigation of scrotal pathology. \\
Hence, in appropriate clinical setting with adequate history and physical examination, it offers specific diagnosis.
\end{tabular}

\section{MATERIALS AND METHODS}

In this series, 100 cases of scrotal pathology were studied using high-frequency real time gray scale ultrasonography and Doppler study, during the period from September 2012 to March 2016, were included in this study.

\section{RESULTS}

In our study, out of 100 cases, 40 cases were detected to have inflammatory scrotal pathology on high frequency US and Doppler study. Chronic epididymo-orchitis was the commonest inflammatory pathology detected, noted in 18 cases (45\%). Next most frequent inflammatory pathology detected was acute epididymo-orchitis noted in nine cases $(22.5 \%)$.

\section{CONCLUSION}

The advantages of high frequency US and colour Doppler includes non-invasiveness, lack of ionising radiation, simplicity, wide availability, cost effectiveness and repeatability.

\section{KEYWORDS}

High Frequency Ultrasonography, Scrotal Swellings, Colour Doppler Sonography.

HOW TO CITE THIS ARTICLE: Raj SMD, Ramakrishna Y, Aithal K. Role of high frequency ultrasound and colour Doppler in evaluation of scrotal pathologies. J. Evolution Med. Dent. Sci. 2017;6(11):862-866, DOI: 10.14260/Jemds/2017/186

\section{BACKGROUND}

Scrotum is a cutaneous bag containing right and left testis, the epididymis and the lower part of the spermatic cord. Externally, scrotum is divided into right and left parts by a ridge or median raphe, which is continued forwards on to the undersurface of the penis and backwards along midline of the perineum to the anus. The testis is separated from the examining fingers by little more than a few millimetre covering of loose skin and fibromuscular tissue, so is most accessible for clinical examination. Consequently, one should pre-suppose that clinical diagnosis of a scrotal swelling would be straight forward. On the contrary, certain testicular swellings are most difficult to diagnose with confidence based on physical examination alone. It is often difficult to decide whether a palpable scrotal mass is arising from the testes itself or from the extratesticular elements. In addition, the normal examination may overlook significant pathology and physical signs elicited may be improperly interpreted.

In the clinical examination of the scrotal swelling, physical evaluation by itself may be inadequate due to tenderness,

Financial or Other, Competing Interest: None.

Submission 23-08-2016, Peer Review 01-11-2016,

Acceptance 07-11-2016, Published 06-02-2017.

Corresponding Author:

Dr. Ramakrishna $Y$

Associate Professor.

Department of General Surgery.

Srinivas Institute of Medical Sciences and Research Centre,

Mukka, Mangalore-574146.

E-mail: gollarama@rediffmail.com

DOI: $10.14260 /$ jemds $/ 2017 / 186$ swelling or gross distortion of scrotal contents. Clinical signs and symptoms are usually nonspecific, variable and misleading. Until mid-1970 clinical evaluation of scrotal contents was confined to palpation, trans-illumination, supplemented by investigative modalities like thermography and venography. The present day diagnostic armamentarium includes gray scale ultrasonography, Doppler studies, Magnetic Resonance Imaging, in addition to Radioisotope studies and Testicular angiography.

Since Miskin and Bain ${ }^{1}$ and Murray Miskin, Martin Buckspan and Jerald Bain ${ }^{2}$ first published report about using diagnostic ultrasound as a modality of investigating scrotal pathologies, advances in instrumentation and transducer design have progressed to the point where high frequency US is the modality of choice in investigating scrotal and testicular pathology. While CT and MRI have dominated imaging of other regions of the body, they have certain limitations in evaluation of scrotal diseases. Computed Tomography delivers radiation to gonads, while MRI imaging is costly and not readily available.

Ultrasonography is exceptionally well suited to study of scrotum and its contents. Sonography is simple to perform, rapid, non-invasive, relatively inexpensive, easily reproducible, widely available and does not involve irradiation of gonads.

The study is done to assess the usefulness of high frequency gray scale US and colour Doppler study in evaluation of various scrotal pathologies. 


\section{Aims and Objectives}

Until the advent of ultrasonography and its application to scrotal imaging, diagnosis of scrotal pathologic conditions traditionally has been based upon the clinical history and physical examination. Definitive diagnosis is not always possible with clinical examination, especially in patients with a marked inflammatory reaction and it is often difficult to decide whether a palpable scrotal abnormality arises from testicle itself or from extratesticular elements in scrotum.

This study will be an effort in establishing the role of high frequency ultrasound as an investigating modality in accurately distinguishing between testicular and extratesticular pathology of scrotum.

High frequency gray scale ultrasonography enables only in identification of morphological alterations that are associated with scrotal disorders. This study will also be an effort in establishing the role of Colour Doppler Sonography in evaluation of scrotal pathology.

\section{Objectives of the Study}

To evaluate scrotal pathology with reference to,

- Assess the role of high frequency real time ultrasonography in accurately distinguishing between testicular and extratesticular scrotal masses.

- Assess the role of Colour Doppler sonography in evaluation of scrotal pathologies.

\section{MATERIALS AND METHODS}

In this series, 100 cases of scrotal pathology was studied using high-frequency real time gray scale ultrasonography and Doppler study, during the period from September 2012 to March 2016 were included in this study. These patients were referred to our Department for scrotal ultrasonography and Doppler study by Department of Urology and Department of Surgery of Srinivas Institute of Medical Sciences and Research Centre, Mukka, Mangalore.

\section{RESULTS}

\begin{tabular}{|c|c|c|c|c|c|c|}
\hline $\begin{array}{c}\text { Sl. } \\
\text { No. }\end{array}$ & Echo Pattern & $\begin{array}{c}\text { Acute } \\
\text { Epididymitis }\end{array}$ & $\begin{array}{c}\text { Acute } \\
\text { Orchitis }\end{array}$ & $\begin{array}{c}\text { Acute } \\
\text { Epididymo- } \\
\text { Orchitis }\end{array}$ & $\begin{array}{c}\text { Chronic } \\
\text { Epididymitis }\end{array}$ & $\begin{array}{c}\text { Chronic } \\
\text { Epididymo- } \\
\text { Orchitis }\end{array}$ \\
\hline 1 & Hyperechoic & & & & 2 & \\
\hline 2 & Hypoechoic & 22 & 3 & 7 & & \\
\hline 3 & Isoechoic & & & 1 & & \\
\hline 4 & Heterogeneous & & & & & 5 \\
\hline 5 & Complex cystic & & & & & \\
\hline 6 & Purely cystic & & & & & 2 \\
\hline 7 & Epididymal calcification & & & & \\
\hline 8 & Testicular calcification & & & & \\
\hline
\end{tabular}

\begin{tabular}{|c|c|c|c|c|c|}
\hline $\begin{array}{c}\text { Colour-Doppler } \\
\text { Appearance }\end{array}$ & $\begin{array}{c}\text { Acute } \\
\text { Epididymitis }\end{array}$ & $\begin{array}{c}\text { Acute } \\
\text { Orchitis }\end{array}$ & $\begin{array}{c}\text { Acute Epididymo- } \\
\text { Orchitis }\end{array}$ & $\begin{array}{c}\text { Chronic } \\
\text { Epididymitis }\end{array}$ & $\begin{array}{c}\text { Chronic } \\
\text { Epididymo- } \\
\text { Orchitis }\end{array}$ \\
\hline Focal increase in Vascularity & & 2 & 2 & 2 & 11 \\
\hline Diffuse increase in Vascularity & 2 & 1 & 7 & 2 & 3 \\
\hline Focal decrease in Vascularity & & & & & 4 \\
\hline Diffuse decrease in Vascularity & & & & \\
\hline Normal Vascularity & \multicolumn{2}{|l}{} \\
\hline \multicolumn{2}{|r|}{ Table 2. Colour Doppler appearance of Inflammatory Scrotal Pathology } \\
\hline
\end{tabular}

\begin{tabular}{|c|c|c|c|}
\hline & Pathology & No. of Cases & \% of Cases \\
\hline 1 & Hydrocoele & 24 & $52 \%$ \\
\hline 2 & Epididymal Cyst & 6 & $7 \%$ \\
\hline 3 & Spermatocoele & 3 & $28 \%$ \\
\hline 4 & Varicocoele & 13 & $\mathbf{1 0 0 \%}$ \\
\hline 5 & Testicular Cyst & $\mathbf{4 6}$ \\
\hline \multicolumn{2}{|c|}{ Total } \\
\hline
\end{tabular}

Among non-neoplastic scrotal swellings, hydrocoele is the commonest pathology noted in 24 cases (54\%). The incidence of nonneoplastic scrotal swellings is very much high compared to neoplastic swellings. Incidence of extratesticular swellings is more compared to intratesticular swellings. High frequency was $100 \%$ sensitive in differentiating intratesticular swellings from extratesticular swellings. 


\begin{tabular}{|c|c|c|c|c|}
\hline Sl. No. & \multicolumn{2}{|c|}{ Clinical Diagnosis } & \multicolumn{2}{|c|}{ High-Frequency US Diagnosis } \\
\hline 1 & Intratesticular & 12 & $\begin{array}{c}\text { Intratesticular } \\
\text { Extratesticular } \\
\text { Both intra + extratesticular }\end{array}$ & $\begin{array}{l}2 \\
6 \\
4\end{array}$ \\
\hline 2 & Extratesticular & 24 & $\begin{array}{c}\text { Extratesticular } \\
\text { Intratesticular } \\
\text { Both intra + extratesticular }\end{array}$ & $\begin{array}{c}18 \\
-- \\
6\end{array}$ \\
\hline 3 & $\begin{array}{l}\text { Both intratesticular } \\
+ \text { extratesticular }\end{array}$ & 6 & $\begin{array}{c}\text { Intratesticular } \\
\text { Extratesticular } \\
\text { Both intra + extratesticular }\end{array}$ & $\begin{array}{l}-- \\
5 \\
1\end{array}$ \\
\hline 4 & No diagnosis & 4 & $\begin{array}{c}\text { Normal } \\
\text { Intratesticular } \\
\text { Extratesticular } \\
\text { Both intra + extratesticular }\end{array}$ & $\begin{array}{l}2 \\
-- \\
2 \\
--\end{array}$ \\
\hline 5 & Unilateral & 32 & $\begin{array}{c}\text { Bilateral } \\
\text { Unilateral }\end{array}$ & $\begin{array}{l}18 \\
16\end{array}$ \\
\hline 6 & Bilateral & 10 & $\begin{array}{c}\text { Unilateral } \\
\text { Bilateral }\end{array}$ & $\begin{array}{l}4 \\
8\end{array}$ \\
\hline
\end{tabular}

The sensitivity and specificity of high-frequency ultrasonography is compared with physical examination in differentiating a scrotal mass as either intratesticular or extratesticular. Present study shows a low sensitivity of physical examination (15\%) and low specificity (50\%), whereas high frequency ultrasonography is highly sensitive and specific (almost 100\%) in differentiating a scrotal mass as either intratesticular or extratesticular compared to physical examination.

\section{Undescended Testis}

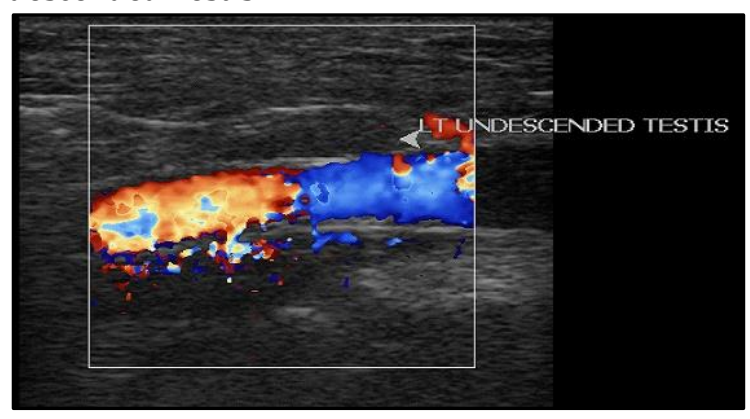

\section{Hematocoele}

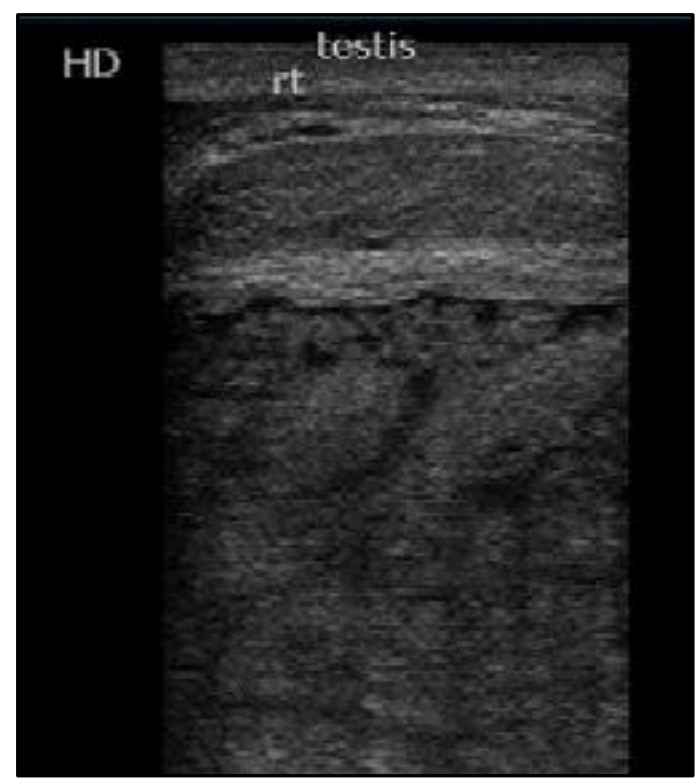

Varicocoele

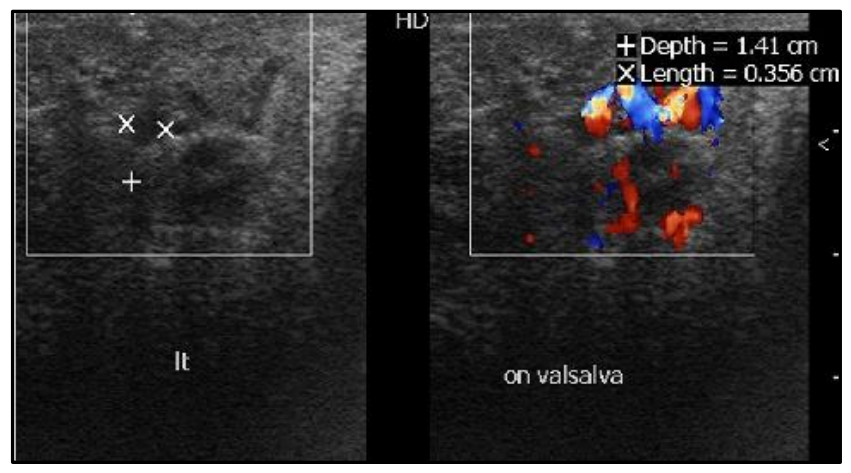

\section{DISCUSSION}

The superficial location of the scrotal contents makes them ideally suited for sonographic examination. The development of high frequency, real time scanners have enhanced the diagnostic accuracy of scrotal sonographic examinations. Scrotal ultrasound has reached a level of maturity that allows the technique to be the first and only imaging examination necessary to evaluate the scrotal contents.

Out of 23 cases of acute onset scrotal swellings, 7 cases (30\%) had h/o trauma, 6 cases (26\%) had h/o dysuria, 2 cases (8\%) had h/o pain abdomen. Other associated symptoms include discharging wound on scrotal skin 5 cases, erythematous skin rashes in 1 case.

In our study, inflammatory conditions constitute the largest number of detected pathology followed by noninflammatory swellings.

\begin{tabular}{|c|c|c|c|}
\hline & $\begin{array}{c}\text { No. of } \\
\text { Cases }\end{array}$ & $\begin{array}{c}\text { Inflammatory } \\
\text { Pathology }\end{array}$ & $\begin{array}{c}\text { Non- } \\
\text { Inflammatory } \\
\text { Pathology }\end{array}$ \\
\hline $\begin{array}{c}\text { Present } \\
\text { Study }\end{array}$ & 132 & $40(30.5 \%)$ & $29(22 \%)$ \\
\hline
\end{tabular}

In our study, the bulk of the pathology detected by highresolution US are from two groups: Inflammatory pathologies and non-inflammatory swellings (69 cases - 52\%), which correlates with findings documented in previous studies 1,16 , 20. However, in our study, we noticed that proportion of Inflammatory pathology is higher, compared to previous studies. Factors contributing for this variation: 
- Higher incidence of chronic inflammatory pathology, especially tubercular aetiology.

- Higher complication rate in our study.

In 1976, Thomas H. Shawker, ${ }^{3}$ reported details of 14 patients scanned with the Picker Echo View VI B-scanner and a $2.25 \mathrm{MHz}$ transducer and concluded that ultrasound Bscanning of the scrotum is a feasible diagnostic study. In 1978 Sample et al, ${ }^{4}$ evaluated a large series of patients with scrotal masses using $5.0 \mathrm{MHz}, 7 \mathrm{~mm}$ diameter transducer with short internal focus produced high quality images of scrotal contents. In 1979, Leopold et al ${ }^{5}$ studied 22 patients referred with a strong clinical suspicion of intra-scrotal pathology. In 1981, Peter H. Arger et al $^{6}$ examined 69 consecutive patients with suspected testicular abnormalities prior to surgery. In 1983, John M. Bockrath et $\mathrm{al}^{7}$ described an ultrasound technique that accurately detected an occult testicular primary in a young man with a large retroperitoneal seminoma.

In 1983, Michael K. Wolverson et al,8 conducted real-time sonography of the scrotal veins in a group of patients who are clinically suspected cases of varicocoele. In 1984, Monica L. Leung et al, ${ }^{9}$ evaluated 40 men who had no known scrotal or testicular symptoms using a real-time dedicated superficial parts scanner (Picker Micro view) $10 \mathrm{MHz}$ transducer.

In 1985, Gregory D. Linkowski et al, ${ }^{10}$ described ultrasonic appearance of scrotal calculi. They used a sector real-time scanner with a $10 \mathrm{MHz}$ transducer. In 1983, Michael K. Wolverson et al ${ }^{11}$ did a comparative study of CT and highresolution ultrasound in localisation of impalpable undescended testis. In 1990, John N. Krieger, Keith Wang and Lawrence Mack ${ }^{12}$ conducted scrotal US study in a group of asymptomatic patients using both real-time, high-resolution gray-scale ultrasound and also Pulsed Doppler ultrasound.

These results indicate that colour Doppler sonography is having high sensitivity (100\%) and positive predilection value (72\%) compared to physical examination. These findings were compared to previous similar study by Randall B. Meacham et al13 and Petros J. A. et al.14 The findings show similarity to previous studies.

In our study of 46 cases of non-inflammatory scrotal swellings, we noted 6 cases of epididymal cysts, 3 cases of spermatocoeles. Out of 6 cases of epididymal cysts, 5 were unilateral, 1 was bilateral and 2 cases showed multiple cysts. Most of the epididymal cysts are uniloculated situated in the head of epididymis, thin walled, anechoic. Associated ipsilateral hydrocoele was noted in 2 cases. In present study, we detected 3 cases of spermatocoeles, which appeared on high frequency US scan as cystic structure with fluid level or fluid-debris level.

In this study, we came across 15 cases of congenital anomalies. Out of this 3 cases $(20 \%)$ were found to be congenital hydrocoele, 4 cases (27\%) were incompletely descended testis and 8 cases (53\%) were undescended testis. The three cases of congenital hydrocoeles were presented in the age group of 2 - 4 years, all were unilateral. These cases were clinically referred as scrotal swelling with suspicion of congenital hernia or congenital hydrocoele.

Of 12 cases of congenital anomaly associated with descent of testes, 7 cases were referred with clinical suspicion of incompletely descended testes, which were clinically palpable. All were unilateral in presentation. Age of presentation varied from 2 years to 26 years with a median age of 3 years. The size of undescended testes found to be smaller in cases, which presented clinically in later stages. Out of this, high frequency US could identify only 4 cases (57\%) of incompletely descended testes, which were in the inguinal region. These testes were small compared to contralateral testes. These were showing normal colour flow on Doppler suggesting viability. Remaining 3 cases of clinically palpable testes were not identified. Among 5 cases of undescended testes, which were clinically not palpable, high frequency US could not identify any of the case of abdominal testis. Among uncooperative younger patients, it is more difficult to identify the undescended testis.

The present study shows that high frequency US is less sensitive in detecting clinically palpable cases and not a reliable diagnostic modality in detecting abdominal ectopic testes.

\section{CONCLUSION AND SUMMARY}

High frequency ultrasonography is highly sensitive in picking up of small, clinically impalpable intratesticular lesions like cyst or small malignant foci. Haematocoele was the most commonly detected traumatic pathology detected in this study.

High frequency ultrasonography is highly sensitive in detecting intratesticular microlithiasis, which cannot be diagnosed clinically. Followup scans are required for such cases because of high incidence of testicular malignancy associated with intratesticular microcalcification.

High frequency ultrasonography with Doppler is highly sensitive in demonstrating the dilated, tortuous veins of pampiniform plexus and flow reversal on Valsalva manoeuvre. When compared to physical examination, it is highly sensitive in detecting sub-clinical cases of varicocoeles.

Ultrasonography is exceptionally well suited to study of scrotum and its contents. The study is done to assess the usefulness of high frequency gray scale US and colour Doppler study in evaluation of various scrotal pathologies.

The advantages of High frequency US and colour Doppler includes non-invasiveness, lack of ionising radiation, simplicity, wide availability, cost effectiveness and repeatability.

High-frequency ultrasonography enables in clear demonstration of morphological alterations associated with acute scrotal inflammatory diseases and colour Doppler sonography is highly sensitive in diagnosing acute scrotal pathology. In addition, colour Doppler sonography accurately differentiates between testicular ischaemia and torsion from acute inflammatory diseases in acute painful scrotal conditions.

High frequency ultrasonography is highly sensitive in differentiating solid from cystic scrotal masses. High frequency ultrasonography is highly sensitive in detecting intratesticular microlithiasis.

High frequency ultrasonography is invaluable in demonstrating normalcy of testes and epididymis in presence of large hydrocoeles.

High frequency ultrasonography with Doppler is highly sensitive in demonstrating the varicocoeles. When compared to physical examination, it is highly sensitive in detecting subclinical cases of varicocoeles.

The advantages of high frequency US and colour Doppler includes non-invasiveness, lack of ionising radiation, 
simplicity, wide availability, cost effectiveness and repeatability.

We conclude that high-frequency ultrasonography and colour Doppler sonography is an extremely valuable tool in evaluation of scrotal and testicular pathologies.

\section{REFERENCES}

[1] Miskin M, Bain J. B-mode ultrasonic examination of the testes. Journal of Clinical Ultrasound 1974;2(4):307-11.

[2] Miskin M, Buckspan M, Bain J. Ultrasonographic examination of scrotal masses. The Journal of Urology 1977;117(2):185-8.

[3] Shawker TH. B-mode ultrasonic examination of scrotal swellings. Radiology 1976;118(2):417-9.

[4] Sample WF, Gottesman JE, Skinner DG, et al. Gray scale ultrasound of the scrotum. Radiology 1978;127(1):2258.

[5] Leopold GR, Woo VL, Scheible FW, et al. High-resolution ultrasonography of scrotal pathology. Radiology 1979;131(3):719-22.

[6] Arger PH, Mulhern CB Jr, Coleman BG, et al. Prospective analysis of the value of scrotal ultrasound. Radiology 1981;141(3):763-6.

[7] Bockrath JM, Schaeffer AJ, Kies MS, et al. Ultrasound identification of impalpable testicle tumor. J of Urol 1983;130(2):355-6.
[8] Wolverson MK, Houttuin E, Heiberg E, et al. Highresolution real-time sonography of scrotal varicocele. AJR 1983;141(4):775-9.

[9] Leung ML, Gooding GA, Williams RD. High-resolution sonography of scrotal contents in asymptomatic subjects. AJR 1984;143(1):161-4.

[10] Linkowski GD, Avellone A, Gooding GA. Scrotal calculi: sonographic detection. Radiology 1985;156(2):484.

[11] Wolverson MK, Houttuin E, Heiberg E, et al. Comparison of computed tomography with high-resolution real-time ultrasound in the localization of the impalpable undescended testis. Radiology 1983;146(1):133-6.

[12] Krieger JN, Wang K, Mack L. Preliminary evaluation of color doppler imaging for investigation of intrascrotal pathology. J of Urol 1990;144(4):904-7.

[13] Meacham RB, Townsend RR, Rademacher D, et al. The incidence of varicoceles in the general population when evaluated by physical examination, gray scale sonography and color doppler sonography. J of Urol 1994;151(6):1535-8.

[14] Petros JA, Andriole GL, Middleton WD, et al. Correlation of testicular color doppler US, physical examination and venography in detection of left sided varicocele in men with infertility. J of Urol 1991;145(4):785. 